\title{
A ESTRUTURAÇÃO E O PAPEL DOS NÚCLEOS PERMANENTES DE MÉTODOS CONSENSUAIS DE SOLUÇÃO DE CONFLITOS: A EXPERIÊNCIA DO TRIBUNAL DE JUSTIÇA DO ESTADO DO MARANHÃO
}

\author{
A STRUCTURE AND THE ROLE OF THE PERMANENT UNCLEUSES OF \\ CONSENSUAL METHODS OF CONFLICT SOLUTION: THE EXPERIENCE OF \\ THE COURT OF JUSTICE OF MARANHÃO
}

\author{
${ }^{1}$ Maria da Glória Costa Gonçalves de Sousa Aquino \\ ${ }^{2}$ Mayco Murilo Pinheiro
}

\section{RESUMO}

O presente trabalho objetiva analisar a estruturação dos Núcleos Permanentes de Métodos Consensuais de Solução de Conflitos a partir das determinações estabelecidas na Resolução CNJ n ${ }^{\circ} 125 / 2010$, que trata da política judiciária de tratamento adequado dos conflitos de interesses. Utilizou-se o método de abordagem indutivo visando analisar a relação existente entre as diretrizes estabelecidas pelo $\mathrm{CNJ}$ e a forma como ocorreu à instituição e o dimensionamento do papel funcional desenvolvido pelo Núcleo Permanente do Tribunal de Justiça do Estado do Maranhão, que atua como protagonista na implantação da política judiciária no âmbito estadual.

Palavras-chave: Meios Consensuais. Solução de Conflitos. Conselho Nacional de Justiça. Desjudicialização. Conflitos de interesses.

\begin{abstract}
This paper aims to analyzing the structure of the Permanent Uncleuses of Consensual Methods of Conflict Solution from the criteria established by the CNJ n ${ }^{\circ} 125 / 2010$ Resolution, which deals with judicial policy of proper handling of conflicts of interest. Utilizes the inductive method of approaching aimed at analyzing the relation existing among the guidelines established by $\mathrm{CNJ}$ and how occurred the institution and the functional role played by the Permanent Uncleuses of the Court of Justice of Maranhão, which acts as protagonist in the implementation of judicial policy at the state level.
\end{abstract}

Keywords: Consensual means. Dispute resolution. Justice National Council. Unjudicialization. Interest Conflicts.

\footnotetext{
${ }^{1}$ Doutora em Políticas Públicas pela Universidade Federal do Maranhão - UFMA, São Luís, (Brasil). Professora Adjunta do curso de Direito da Universidade Federal do Maranhão UFMA. E-mail: mgcgn@email.iis.com.br

2 Pós-Graduado em Direito Público pela Universidade Cândido Mendes - FACAM, Rio de Janeiro, (Brasil). Analista Judiciário do TJ/MA. Professor do curso de Direito da Universidade Ceuma, Maranhão. E-mail: mmpinheiro.ma@gmail.com
} 


\title{
1 INTRODUÇÃO
}

A partir do momento em que foi promulgada a CRFB/88, o Poder Judiciário brasileiro passou a enfrentar uma sobrecarga de processos provenientes do excesso de conflitos existentes na sociedade. ${ }^{3}$

Em razão da estrutura burocratizada e calcificada do Poder Judiciário, a prestação jurisdicional se caracterizou como lenta e insatisfatória à urgente resposta que a sociedade exigia. A morosidade no desempenho da atividade do Poder Judiciário gerou uma ausência de credibilidade quanto ao papel desenvolvido por este junto à sociedade.

Era necessário reverter esse quadro de afastamento do Judiciário e de incredulidade sobre as atividades e ações por ele desempenhadas. A aproximação do Judiciário com a população brasileira era medida urgente que deveria ser buscada.

Em 23 de abril de 2010, quando tomou posse como presidente do Supremo Tribunal Federal (STF), o ministro Cezar Peluso manifestou sua grande preocupação sobre os problemas existentes e que deveriam ser enfrentados pelo Poder Judiciário brasileiro. Em seu discurso de posse, já se verificava o novo direcionamento a ser dado aos problemas vivenciados pelo Poder Judiciário brasileiro:

\begin{abstract}
O mecanismo judicial, hoje disponível para dar-lhes resposta, é a velha solução adjudicada, que se dá mediante produção de sentenças e, em cujo seio, sob influxo de um arraigada cultura de dilação, proliferam os recursos inúteis e as execuções extremamente morosas e, não raro, ineficazes. É tempo, pois, de, sem prejuízo doutras medidas, incorporar ao sistema os chamados meios alternativos de resolução de conflitos, que, como instrumental próprio, sob rigorosa disciplina, direção e controle do Poder Judiciário, sejam oferecidos aos cidadãos como mecanismos facultativos de exercício da função constitucional de resolver conflitos. Noutras palavras, é preciso institucionalizar, no plano nacional, esses meios como remédios jurisdicionais facultativos, postos alternativamente à disposição dos jurisdicionados, e de cuja adoção o desafogo dos órgãos judicantes e a maior celeridade dos processos, que já serão avanços muito por festejar, representarão mero subproduto de uma transformação social ainda mais importante, a qual está na mudança de mentalidade em decorrência da participação decisiva das próprias partes na construção de resultado que, pacificando, satisfaça seus interesses (PELUSO, 2015).
\end{abstract}

No teor de seu discurso percebia-se com clareza uma inclinação para se promover um afastamento dos conflitos de interesses da exigência de uma solução adjudicada por meio da sentença judicial. A direção apontada pelo próprio Poder Judiciário primava pela obtenção da pacificação social pela utilização de mecanismos alternativos de solução de conflitos.

\footnotetext{
${ }^{3}$ De acordo com o Sumário executivo do Relatório Justiça em Números, em 2009, tramitaram em torno de 86,6 milhões de processos nas três esferas de Justiça - federal, estadual e do trabalho, considerando-se nesse quantitativo a soma de casos novos e dos processos pendentes de baixa definitiva (BRASIL, 2010b).
} 
O que se nota é que o Poder Judiciário tomou a iniciativa de promover uma alteração na forma com que os conflitos de interesses eram recepcionados e resolvidos na sociedade brasileira. Com isso, o Judiciário caminhava para o redimensionamento de uma nova interpretação do princípio da inafastabilidade jurisdicional a que alude o inciso XXXV do art. $5^{\circ}$ da CRFB/88. Mediante essa nova concepção, o Poder Judiciário passaria a exercer um novo protagonismo, endógeno, visto que ocorre no corpo estrutural e funcional do próprio Poder Judiciário brasileiro.

Ao iniciar os trabalhos na presidência do Supremo Tribunal Federal e, consequentemente, junto ao Conselho Nacional de Justiça (CNJ), o min. Cezar Peluso nomeou um grupo de trabalho, composto eminentemente por magistrados, para elaborar uma política pública de tratamento adequado dos conflitos de interesses. As orientações e as concepções extraídas por esse grupo de trabalho resultaram na criação da Resolução CNJ n 125 , de 29 de novembro de 2010 (BRASIL, 2010c), que institucionalizou a política judiciária nacional de tratamento adequado dos conflitos de interesses no âmbito do Poder Judiciário.

Desta forma, o grupo de trabalho elaborou a política estabelecendo mecanismos de filtragem ao acesso à justiça com o propósito de possibilitar o gerenciamento do acervo processual pelo Judiciário brasileiro. Nesse aspecto, ressai as considerações de Gabbay e Cunha (2012, p. 18-19) sobre o assunto:

\begin{abstract}
A morosidade, como revelam tanto as pesquisas de opinião como os dados disponíveis, se constitui em um dos mais graves problemas do Judiciário. Trata-se da crítica mais longeva e constante. A lentidão expressa nas taxas de congestionamento é, de fato, muito expressiva, provocando consequências que vão desde a descrença na instituição até impactos nos padrões de civilidade. Assim, os efeitos advindos do problema da morosidade não necessitariam de maiores explicações para justificar sua inclusão entre os temas prioritários de pesquisa. O enfrentamento dessa questão depende fundamentalmente da identificação dos principais gargalos, de suas causas e das possibilidades de solução.
\end{abstract}

A Resolução CNJ n 125/2010 passou a regulamentar a mediação e a conciliação meios consensuais de solução de conflitos de interesse, como sendo instrumentos tendentes à pacificação social, à solução e à prevenção de litígios, no desígnio de conter a litigiosidade processual, como também, instituiu um novo modelo de atuação do Poder Judiciário, focalizado numa diferente forma de gerenciamento e estruturação. Isto é, a Resolução CNJ n ${ }^{\circ}$ 125/2010 estrutura a política pública a partir dos Núcleos Permanentes de Métodos Consensuais de Solução de Conflitos e dos Centros Judiciários de Solução de Conflitos e Cidadania que exercem funções específicas. 
Essa reformulação estrutural definida pela política pública de tratamento adequado dos conflitos de interesses possibilita a criação do que Bourdieu (2007, p. 135), metodologicamente, identifica como sendo novos “campos sociais". Nessa nova estrutura se inserem os Núcleos Permanentes de Métodos Consensuais de Solução de Conflitos e os Centros Judiciários de Solução de Conflitos e Cidadania.

Enquanto os Centros se atêm à prática dos métodos consensuais de solução de conflitos, ou seja, ficam responsáveis pela execução da política junto à sociedade e pela ampliação da orientação jurídica aos cidadãos brasileiros, os Núcleos Permanentes atuam politicamente, desenvolvendo a política no âmbito regional/estadual, estabelecendo a interlocução com outros Tribunais e órgãos integrantes, e promovendo a capacitação dos magistrados, servidores, conciliadores e mediadores.

\section{OS NÚCLEOS PERMANENTES DE MÉTODOS CONSENSUAIS DE SOLUÇÃO DE CONFLITOS}

O Conselho Nacional de Justiça, quando implementou a Política Judiciária Nacional de tratamento adequado dos conflitos de interesses, apontou como diretriz que a aplicação dos métodos consensuais de solução de conflitos deve ser vista como prática duradoura, e não somente como uma política transitória, de natureza emergencial, visando, tão somente, promover o contingenciamento das demandas que se encontram em curso na Justiça brasileira.

A definição desse novo paradigma conferiu a devida relevância da política de enfrentamento dos conflitos de interesses, como se observa na interpretação do art. $2^{\circ}$ da Resolução CNJ n ${ }^{\circ} 125 / 2010,{ }^{4}$ que definiu as três bases estruturais nas quais se encontra assentada a política pública judiciária de tratamento adequados dos conflitos de interesses. São elas: a centralização das estruturas judiciárias, a adequada formação e treinamento de servidores, conciliadores e mediadores, bem como o acompanhamento estatístico específico.

\footnotetext{
${ }^{4}$ Art. $2^{\circ}$ da Resolução CNJ n 125/2010 (texto original): "Na implementação da Política Judiciária Nacional, com vistas à boa qualidade dos serviços e à disseminação da cultura de pacificação social, serão observados: centralização das estruturas judiciárias, adequada formação e treinamento de servidores, conciliadores e mediadores, bem como acompanhamento estatístico específico" (BRASIL, 2010c). Na nova redação dada pela Emenda CNJ n ${ }^{\circ} 1 / 2013$ ao art. $2^{\circ}$ da Resolução CNJ n ${ }^{\circ} 125 / 2010$, o texto passou a ter a seguinte redação: "Na implementação da Política Judiciária Nacional, com vistas à boa qualidade dos serviços e à disseminação da cultura de pacificação social, serão observados: I - centralização das estruturas judiciárias; II - adequada formação e treinamento de servidores, conciliadores e mediadores; III - acompanhamento estatístico específico" (BRASIL, 2013).
} 
Esses pilares estruturais norteiam o modo de organização da política pública de tratamento adequado dos conflitos de interesses, tanto no âmbito nacional quanto na esfera regional. $\mathrm{O}$ que equivale dizer que as medidas apenas conferiram a sistematização generalizada da política, norteando as ações e atuações a serem executadas pelos tribunais de todo o país. A respeito, destaca-se o entendimento de Nogueira (2011, p. 252):

\begin{abstract}
Nesse aspecto, a Resolução, por seu artigo $6^{\circ}$, atribui ao Conselho Nacional de Justiça, auxiliado pelo Comitê Gestor da Conciliação, o desenvolvimento de diretrizes nacionais para implementação da política pública de tratamento adequado de solução de conflitos, definindo parâmetros e padrões gerais de atuação e sistematização que devem ser seguidos pelos Tribunais, destacando, ainda, seu papel de interlocutor nacional entre os diversos segmentos do Poder Judiciário e instituições públicas e privadas, e de incentivador à disseminação e à valorização das práticas autocompositivas.
\end{abstract}

Há de se ressaltar que o art. $4^{\circ}$ da Resolução CNJ n ${ }^{\circ} 125 / 2010^{5}$ atribuiu ao próprio Conselho Nacional de Justiça a responsabilidade pela promoção dos programas e ações de incentivo à autocomposição de litígios e à pacificação. E incumbiu o CNJ a auxiliar os tribunais na organização dos serviços que visem a assegurar o direito à solução adequada dos conflitos de interesses, como se verifica na dicção dada pelo art. $3^{\circ}$ da Resolução CNJ n ${ }^{\circ} 125 / 2010$. $^{6}$

Contudo, antes da criação da Resolução CNJ n 125/2010, a divulgação e incentivo da solução de conflitos por meio da conciliação, como também a organização e implementação de ação para a Semana Nacional de Conciliação cabiam ao Comitê Gestor da Conciliação, instituído por meio da Portaria n 637 de 09 de outubro de 2009 (BRASIL, 2009).

Seguindo o caminho da concretização de uma política nacional de conciliação, o então presidente do Conselho Nacional de Justiça, ministro Cezar Peluso, editou a Portaria $\mathrm{n}^{\circ} 141$, de 20 de julho de $2010^{7}$ (BRASIL, 2010a), constituindo o Grupo de Trabalho para a realização de estudos e propostas de ações visando à implementação da política pública judiciária nacional.

\footnotetext{
${ }^{5}$ Art. $4^{\circ}$ da Resolução CNJ n 125/2010: "Compete ao Conselho Nacional de Justiça organizar programa com o objetivo de promover ações de incentivo à autocomposição de litígios e à pacificação social por meio da conciliação e da mediação" (BRASIL, 2010c).

${ }^{6}$ Art. $3^{\circ}$ da Resolução CNJ n 125/2010: "O CNJ auxiliará os tribunais na organização dos serviços mencionados no art. $1^{\circ}$, podendo ser firmadas parcerias com entidades públicas e privadas" (BRASIL, 2010c).

7 A Portaria ${ }^{\circ} 141$, de 20 de julho de 2010 foi posteriormente revogada pela Portaria $\mathrm{n}^{\circ} 110$, de 14 de outubro de 2011, que também instituiu grupo de trabalho para a realização de estudos e propostas de ações com vistas à concretização de uma política nacional de conciliação. A diferença entre ambas reside no fato de que a primeira foi destinada à elaboração de modelagem de juízos de conciliação e mediação e à apresentação de propostas de tratamento de demandas de massa, enquanto que a segunda teve como objetivo dar continuidade ao projeto de divulgação e incentivo da solução de conflitos por meio da conciliação, bem como organizar e implementar ações para a Semana Nacional da Conciliação.
} 
Através da Resolução CNJ n $125 / 2010$ atribuiu, definitivamente, ao Conselho Nacional de Justiça a fixação de diretrizes nacionais para a implementação da política pública judiciária de tratamento adequado dos conflitos de interesses (inciso I do art. $6^{\circ}$ da Resolução $\mathrm{CNJ} \mathrm{n}^{\circ} 125 / 2010^{8}$ ).

Merece destaque o papel desempenhado pelo Comitê Gestor da Conciliação, que contribuiu sobremaneira para a criação da política pública judiciária de tratamento adequado dos conflitos de interesses no âmbito nacional e auxiliou o Conselho Nacional de Justiça durante a implementação da política judiciária no direcionamento das ações focadas na solução dos conflitos por meio dos métodos consensuais.

Portanto a Resolução CNJ n 125/2010 inovou na medida em que delimitou o papel desempenhado pelo Conselho Nacional de Justiça que, juntamente com o auxílio do Comitê Gestor da Conciliação, assumiu a incumbência de auxiliar os tribunais na organização estrutural e funcional, visando assegurar o direito à solução dos conflitos através dos métodos consensuais de solução de conflitos.

Apesar da abrangência e da definição das diretrizes nacionais ficarem a cargo do CNJ, cuja atribuição confere maior centralidade ao programa e, sobretudo, às ações propostas no âmbito nacional, é através dos Tribunais que a política judiciária adquire um formato regional.

São os tribunais que atuam como órgãos vinculados ao Conselho Nacional de Justiça e, em consequência, ao Poder Judiciário, e que assumem a responsabilidade de dar cumprimento e implementar, no âmbito interno das justiças federal e estadual, a Resolução CNJ nº 125/2010.

Observa-se, com isso, que o Conselho Nacional de Justiça transfere a responsabilidade pelo êxito ou fracasso da implementação da política judiciária aos tribunais, ao mesmo tempo em que continua exercendo uma fiscalização e controle sobre as atividades e ações exercidas pelos tribunais, através do estabelecimento de metas de produtividade.

A política pública judiciária de tratamento adequado de conflitos de interesses se desenhou no âmbito estadual e federal por meio dos Tribunais, uma vez que o art. $7^{\circ}$ da Resolução CNJ n ${ }^{\circ}$ 125/2010 ${ }^{9}$ atribuiu a eles a criação dos Núcleos Permanentes de Métodos

\footnotetext{
${ }^{8}$ Art. $6^{\circ}$ da Resolução CNJ n 125/2010: "Para desenvolvimento dessa rede, caberá ao CNJ: I - estabelecer diretrizes para implementação da política pública de tratamento adequado de conflitos a serem observadas pelos Tribunais; [...]" (BRASIL, 2010c).

${ }^{9}$ Art. $7^{\circ}$ da Resolução CNJ n ${ }^{\circ}$ 125/2010: "Os Tribunais deverão criar, no prazo de 30 dias, Núcleos Permanentes de Métodos Consensuais de Solução de Conflitos, compostos por magistrados da ativa ou aposentados e servidores, preferencialmente atuantes na área, com as seguintes atribuições, entre outras: [...]" (BRASIL, 2010c).
} 
Consensuais de Solução de Conflitos (Núcleos) ${ }^{10}$ com o propósito de desenvolver a política judiciária baseada nas diretrizes e orientações estabelecidas pela Resolução CNJ n 125/2010.

O Conselho Nacional de Justiça atribuiu aos tribunais o dever de informarem ao CNJ a criação formal e a composição dos Núcleos. ${ }^{11}$

O CNJ não impôs aos tribunais qualquer obrigação de informar eventuais mudanças e alterações na composição dos Núcleos. Porém entendemos que o parágrafo único do art. $7^{\circ}$ da Resolução CNJ n 125/2010 (atual parágrafo $1^{\circ}$ do art. $7^{\circ}$ Resolução CNJ n 125/2010, em razão da alteração motivada pela Emenda CNJ $n^{\circ}$ 1/2013) deve ser interpretado de modo extensivo, uma vez que qualquer alteração no âmbito da administração dos Núcleos irá afetar a condução dos trabalhos e execução das ações desenvolvidas pelos tribunais, especialmente perante o Conselho Nacional de Justiça.

No que concerne à composição dos Núcleos Permanentes de Métodos Consensuais de Solução de Conflitos (Núcleos), o mesmo art. $7^{\circ}$ da Resolução CNJ n 125/2010 dispõe que poderão "compô-los os magistrados da ativa ou aposentados e servidores, preferencialmente atuantes na área" (BRASIL, 2010c).

Observa-se aqui uma tentativa do Conselho Nacional de Justiça de ampliar e diversificar a composição dos Núcleos, seja permitindo a participação de juízes que se encontram na ativa, seja possibilitando a atuação daqueles que já se encontram aposentados, e que possuem uma profunda experiência da prática conciliatória adquirida ao longo dos anos de atuação profissional.

Outro ponto que merece destaque diz respeito ao fato de que a Resolução $\mathrm{CNJ} \mathrm{n}^{\circ}$ 125/2010 não restringiu a participação dos magistrados que se encontram na ativa por área de atuação. Sem embargo, essa ausência de restrição possibilita a participação dos magistrados que atuam em diferentes áreas. Veja-se que o único requisito definido pela Resolução CNJ ${ }^{\circ}$

\footnotetext{
${ }^{10} \mathrm{O}$ art. $7^{\circ}$ da Resolução $\mathrm{CNJ} \mathrm{n}^{\circ}$ 125/2010 (texto original) definiu o prazo de 30 (trinta) dias para que os Tribunais criassem os Núcleos Permanentes de Métodos Consensuais de Solução de Conflitos (BRASIL, 2010c). Entretanto, muitos tribunais de nosso país não conseguiram cumprir o prazo trintídio concedido pelo Conselho Nacional de Justiça (CNJ) para a criação dos Núcleos. Como exemplo podemos citar o Tribunal de Justiça do Maranhão, que somente instituiu o órgão no âmbito da justiça estadual, através da Resolução-GP-102011, em 16 de março de 2011 (MARANHÃO, 2011). Verificando esse problema, a Emenda CNJ n ${ }^{\circ}$ 1/2013 ampliou o prazo para 60 (sessenta) dias, passando a nova redação do caput do art. $7^{\circ}$ da Resolução CNJ n ${ }^{\circ}$ 125/2010 a configurar da seguinte forma: "Os Tribunais deverão criar, no prazo de 60 (sessenta) dias, Núcleos Permanentes de Métodos Consensuais de Solução de Conflitos, compostos por magistrados da ativa ou aposentados e servidores, preferencialmente atuantes na área, com as seguintes atribuições, entre outras: [...]" (BRASIL, 2013).

${ }^{11}$ Art. $7^{\circ}$ da Resolução $\mathrm{CNJ}$ n $^{\circ}$ 125/2010 (texto original): [...]. Parágrafo único: "A criação dos Núcleos e sua composição deverão ser informadas ao Conselho Nacional de Justiça" (BRASIL, 2010c). O teor do parágrafo único não foi alterado pela Emenda $\mathrm{CNJ} \mathrm{n}^{\circ} 1 / 2013$, mas realocado para o parágrafo $1^{\circ}$ do art. $7^{\circ}$ da Resolução $\mathrm{CNJ}^{\circ} 125 / 2010$
} 
125/2010 em relação à composição dos Núcleos foi de contemplar a possibilidade da atuação de magistrados que se encontram na ativa e também daqueles que já estão aposentados, como já mencionamos anteriormente.

Conquanto, entende-se que a Resolução CNJ n 125/2010 não definiu regras mais específicas a serem aplicadas, especialmente nas esferas nacional e regional, em relação à escolha dos magistrados, pois via de regra a escolha desses magistrados é determinada aleatoriamente, ou até mesmo condicionada à atuação política desses magistrados junto à administração dos tribunais do país, ou seja, a escolha dos componentes dos Núcleos Permanentes não depende de critérios técnicos que envolvam profundo conhecimento das práticas autocompositivas e aplicação de métodos alternativos de solução de controvérsias.

A redação original da Resolução CNJ n 125/2010 também não considerou a atuação dos magistrados nos Núcleos como requisito ou critério de merecimento para promoções e remoções dos magistrados. Porém a Emenda CNJ n $n^{\circ} 1 / 2013$ inseriu o $\S 8^{\circ}$ ao art. $8^{\circ}$ da Resolução CNJ n ${ }^{\circ}$ 125/2010, possibilitando que as sentenças homologatórias prolatadas pela solicitação de feitos de outras unidades judiciais sejam revertidas ao juízo de origem e as sentenças decorrentes da atuação pré-processual sejam revertidas ao coordenador do Centro. De acordo com a Resolução CNJ n ${ }^{\circ} 125 / 2010$, essa medida tem como fim a estatística de produtividade que, por sua vez, serve como critério a possíveis promoções e remoções dos magistrados.

Interessante seria se a escolha levasse em consideração a atuação prévia desses magistrados nas áreas que permitem a utilização dos métodos alternativos, como a conciliação e a mediação. São elas: família, previdenciária, juizados especiais, cível em geral, aquelas que envolvem os sistemas educacionais (FIES) e de saúde, o sistema financeiro de habitação e fazenda pública.

Ainda no que tange à composição dos Núcleos Permanentes, a Resolução CNJ $n^{\circ}$ 125/2010 contemplou a possibilidade de participação de servidores que, especialmente, prestam serviços administrativos de assessoramento, possibilitando uma interface com setores dos próprios tribunais, do Conselho Nacional de Justiça e dos Centros Judiciários de Solução de Conflitos e Cidadania (Centros).

Há de se ressaltar que o Conselho Nacional de Justiça, ao atribuir aos tribunais a competência para a criação dos Núcleos, reconheceu o grande protagonismo exercido pelos tribunais brasileiros, sobretudo no que diz respeito à implementação da política judiciária 
regional e/ou estadual e à definição das metas a serem alcançadas durante a execução da política pública judiciária.

Em paralelo, ressalta-se o papel desempenhado pelos Núcleos, que exercem, na esfera regional e/ou estadual, uma função eminentemente política dentro da política pública judiciária de tratamento adequado dos conflitos de interesses, visando a cooptação e estreitamento da interlocução junto os demais órgãos do Poder Judiciário, das entidades públicas e privadas parceiras, tais como universidades públicas e privadas, Ministério Público, Defensoria Pública, Procuradorias do Estado e do Município, Advocacia Geral da União, Procon's e a Ordem dos Advogados do Brasil, aqui compreendidas as seccionais e as subseções.

Além do papel político desempenhado pelos Núcleos, o art. $7^{\circ}$ da Resolução CNJ $n^{\circ}$ 125/2010 (texto original) definiu explicitamente as suas atribuições, das quais se destacam: I) desenvolver a Política Judiciária de tratamento adequado dos conflitos de interesses; II) planejar, implementar, manter e aperfeiçoar as ações voltadas ao cumprimento da política e suas metas; III) atuar na interlocução com outros Tribunais e com os órgãos integrantes da rede mencionada nos arts. $5^{\circ}$ e $6^{\circ}$ da Resolução CNJ n 125/2010; IV) instalar Centros Judiciários de Solução de Conflitos e Cidadania que concentrarão a realização das sessões de conciliação e mediação que estejam a cargo de conciliadores e mediadores, dos órgãos por eles abrangidos; V) promover capacitação, treinamento e atualização permanente de magistrados, servidores, conciliadores e mediadores nos métodos consensuais de solução de conflitos; VI) criar e manter cadastro, de forma a regulamentar o processo de inscrição e de desligamento de conciliadores e mediadores que atuem em seus serviços; VII) regulamentar, se for o caso, a remuneração de conciliadores e mediadores nos termos da legislação específica; VIII) incentivar a realização de cursos e seminários sobre mediação e conciliação e outros métodos consensuais de solução de conflitos; IX) firmar, quando necessário, convênios e parcerias com entes públicos e privados (BRASIL, 2010c).

A Emenda $\mathrm{CNJ} \mathrm{n}^{\circ}$ 1/2013 alterou as atribuições inicialmente conferidas aos Núcleos. Basicamente, houve um pequeno acréscimo no inciso $\mathrm{V}$ e foram suprimidos os incisos VI a IX, todos relativos ao art. $7^{\circ}$ da Resolução CNJ n 125/2010. Além de terem sido acrescentados quatro parágrafos, substituindo o parágrafo único vigente na época da implementação da política pública.

Dessa forma, a nova redação definiu como atribuições dos Núcleos as seguintes atividades: I) desenvolver a Política Judiciária de tratamento adequado dos conflitos de 
interesses, estabelecida na Resolução; II) planejar, implementar, manter e aperfeiçoar as ações voltadas ao cumprimento da política e suas metas; III) atuar na interlocução com outros Tribunais e com os órgãos integrantes da rede mencionadas nos arts. $5^{\circ}$ e $6^{\circ}$; IV) instalar Centros Judiciários de Solução de Conflitos e Cidadania, que concentrarão a realização das sessões de conciliação e mediação que estejam a cargo de conciliadores e mediadores dos órgãos por eles abrangidos; V) incentivar ou promover capacitação, treinamento e atualização permanente de magistrados, servidores, conciliadores e mediadores nos métodos consensuais de solução de conflitos; VI) propor ao Tribunal a realização de convênios e parcerias com entes públicos e privados para atender aos fins da Resolução (BRASIL, 2013).

Com tais atribuições os Núcleos assumem a função de coesão das práticas e ações direcionadas à autocomposição dos conflitos de interesses na esfera regional e/ou estadual. Para Luchiari (2011, p. 235), a atuação dos Núcleos pode compreender ainda uma gama de atividades que excedem aquelas elencadas no art. $7^{\circ}$ da Resolução CNJ n 125/2010:

\begin{abstract}
Dentre as funções que não constam expressamente da Resolução, mas que podem ser atribuídas ao "Núcleo", destacam-se: 1) a indicação, ao presidente do Tribunal de Justiça, dos juízes aptos a atuar como coordenadores e adjuntos (se necessário) dos Centros Judiciários de Solução de Conflitos e Cidadania, entre aqueles que realizaram o treinamento exigido pelo artigo $9^{\circ} ; 2$ ) a gestão perante o Tribunal de Justiça para que as atividades relacionadas aos métodos consensuais de solução de conflitos sejam consideradas nas promoções e remoções de magistrados, pelo critério de merecimento, e no plano de carreira dos servidores; 3) o acompanhamento legislativo de projetos voltados aos métodos consensuais de solução de conflitos; 4) a decisão e apreciação, com exclusividade, de todos os expedientes e processos afetos aos métodos consensuais de solução de conflitos, bem como a instalação e desativação de órgãos voltados ao trabalho com tais métodos no âmbito do Tribunal de Justiça; 5) a solução de dúvidas e a resposta às consultas, de magistrados e servidores, atinentes aos métodos consensuais de solução de conflitos e sua utilização no âmbito do Poder Judiciário; 6) a criação e controle do banco de dados das atividades desenvolvidas pelos “Centros", nos moldes previstos no seu Anexo IV, e a divulgação dos resultados.
\end{abstract}

Constata-se que são atribuídas aos Núcleos Permanentes de Métodos Consensuais de Solução de Conflitos funções diversificadas e que cabe aos tribunais especificá-las no âmbito interno de acordo com a orientação para o desenvolvimento da política judiciária na esfera regional e/ou estadual.

Diante da diversidade de atividades, faz-se imperioso que os Núcleos contem com um espaço físico próprio e uma estrutura funcional adequada ao desenvolvimento das funções e desempenho salutar dos trabalhos, ações e programas. A escolha desse espaço cabe aos tribunais haja vista a natureza vinculativa das atividades direcionadas à política judiciária de tratamento adequado dos conflitos de interesses. 
Ademais, os Núcleos são os responsáveis pela materialização da política pública judiciária, desenvolvendo concretamente o gerenciamento dos trabalhos junto aos Centros Judiciários de Solução de Conflitos e Cidadania (Centros), onde serão executadas as atividades direcionadas às práticas autocompositivas de solução dos conflitos de interesses.

Isso significa dizer que, os Núcleos exercem uma função política junto aos tribunais, exercendo um controle administrativo sobre o planejamento e o gerenciamento das ações e metas para o cumprimento da política judiciária. Ademais, os Núcleos atuam na interlocução entre os tribunais e os Centros, como também, junto às instituições parceiras, ou seja, tem a incumbência de intermediar a execução de ações específicas que visem a desjudicialização dos conflitos.

Nesse sentido, observa-se que mais uma vez há o deslocamento de responsabilidades na política judiciária de tratamento adequado dos conflitos de interesses, uma vez que os tribunais deslocam aos Núcleos as atribuições políticas pela promoção das ações voltadas ao cumprimento da política.

\section{O NÚClEO PERMANENTE DE MÉTOdOS CONSENSUAIS DE SOLUÇÃO DE CONFLITOS DO TRIBUNAL DE JUSTIÇA DO ESTADO DO MARANHÃO}

Como já mencionado, caberá aos tribunais a criação dos Núcleos Permanentes, bem como estabelecer uma estrutura física e a designação de servidores com aptidão para desenvolver as atividades assinaladas pela política judiciária, especialmente no âmbito regional e/ou estadual.

Portanto os Núcleos são órgãos vinculados à Justiça Estadual ou Federal, que estabelecem e definem as ações tendentes ao atingimento das metas e ao direcionamento setorial da política judiciária no âmbito de cada Estado e/ou Região judiciária. Dentre os diversos Núcleos instituídos pelos Tribunais de Justiça em todo o país, destacamos no presente trabalho, como mero exemplo, a composição e as atribuições definidas ao Núcleo do Tribunal de Justiça do Estado do Maranhão (TJMA).

O Núcleo Permanente de Métodos Consensuais de Solução de Conflitos encontra-se vinculado ao Tribunal de Justiça do Estado do Maranhão e foi criado por meio da ResoluçãoGP-102011, em 16 de março de 2011 (MARANHÃO, 2011). Sua atuação consiste em auxiliar a Presidência do Tribunal de Justiça do Estado na promoção de ações direcionadas à política 
judiciária de tratamento adequado dos conflitos de interesses e de difusão das práticas autocompositivas que busquem a resolução dos conflitos.

Além disso, o Núcleo Permanente atua como órgão político da política pública judiciária estadual de tratamento adequado dos conflitos de interesses.

Inicialmente intitulado como NUPECON ${ }^{12}$, o Núcleo Permanente de Métodos Consensuais de Solução de Conflitos foi composto por magistrados no desempenho ativo de suas funções e servidores vinculados ao Tribunal de Justiça do Estado do Maranhão.

Atualmente a Portaria-GP-2082012 (MARANHÃO, 2012), editada pelo então presidente do Tribunal de Justiça do Estado do Maranhão, desembargador Antônio Guerreiro Júnior, regulamenta a designação do Núcleo Permanente de Métodos Consensuais de Solução de Conflitos na esfera estadual, abrangendo em sua composição os seguintes membros: desembargador José Luiz Oliveira de Almeida, que atua como presidente do Núcleo; os juízes de Direito, Dr. Nelson Melo de Moraes Rêgo, Dra. Márcia Cristina Coelho Chaves, Dr. Alexandre Lopes de Abreu e Dr. Antônio Luiz de Almeida Silva; e a servidora Josiane de Jesus Fonseca.

As atribuições do Núcleo Permanente estadual (NUPECON) foram definidas pelo art. $1^{\circ}$ da Resolução-GP-102011, cuja abrangência compreende: 1) desenvolver a política judiciária de tratamento adequado dos conflitos de interesses, na forma da Resolução CNJ n 125/2010; 2) planejar, implementar, manter e aperfeiçoar as ações voltadas ao cumprimento da política e sua metas; 3) atuar na interlocução com outros Tribunais e com as instituições públicas e privadas parceiras; 4) propor à Presidência do Tribunal a criação e instalação de Centros Judiciários de Solução de Conflitos e Cidadania, que concentrarão a realização das sessões de conciliação e mediação que estejam a cargo de conciliadores e mediadores; 5) promover a capacitação, treinamento e atualização permanente de magistrados, servidores, conciliadores e mediadores nos métodos consensuais de solução de conflitos; 6) criar e manter cadastro de conciliadores e mediadores que atuem em seus serviços, de forma a regulamentar o processo de inscrição e de desligamento; 7) incentivar a realização de cursos e seminários e outros métodos consensuais de solução de conflitos; 8) propor à Presidência do Tribunal a assinatura de convênios e parcerias com entes públicos e privados, para atender aos fins propostos pela Resolução CNJ n 125/2010 (MARANHÃO, 2011).

\footnotetext{
${ }^{12}$ Cabe esclarecer que no Relatório de Gestão desenvolvido pelo Núcleo Permanente de Métodos Consensuais de Solução de Conflitos e divulgado no site do Tribunal de Justiça do Estado do Maranhão encontra-se a sigla NPMCSC como referência ao Núcleo Permanente estadual.
} 
Em síntese, constata-se que o Tribunal de Justiça do Estado do Maranhão se limitou a reproduzir as competências definidas pelo Conselho Nacional de Justiça na redação original dada à Resolução CNJ n ${ }^{\circ}$ 125/2010, excetuando-se a atribuição prevista no inciso VII do art. $7^{\circ}$ da Resolução CNJ n 125/2010, que compreende a possibilidade de regulamentação da remuneração de conciliadores e mediadores por legislação específica.

Desde a criação do Núcleo Permanente de Métodos Consensuais de Solução de Conflitos do Tribunal de Justiça do Estado do Maranhão em 2011, somente foi divulgado um único Relatório de Gestão no Portal do Poder Judiciário do Estado do Maranhão, que compreendeu o desenvolvimento de atividades durante o biênio de 2012/2013 (MARANHÃO, 2013).

Entende-se que, o carecimento de formas de divulgação das atividades desempenhadas na esfera estadual compromete o trabalho desenvolvido pelo Núcleo, pois dificulta o acesso da sociedade maranhense e todos os demais interessados nas ações que envolvem as práticas autocompositivas de solução de conflitos de interesses.

É preciso que o Judiciário olvide esforços no sentido de aprimorar a forma de divulgação dos dados e das ações desempenhadas. O lançamento de informações e estatísticas sobre o quantitativo de audiências realizadas, a quantidade de acordos obtidos, o quantitativo de audiências visando à obtenção de soluções consensuais sobre demandas repetitivas, entre outros dados, facilitam uma apuração mais precisa acerca da política judiciária.

No caso do Estado Maranhão, verifica-se que há uma defasagem na divulgação das informações, a qual pode ser constatada no mero acesso ao sítio eletrônico do Tribunal de Justiça do Estado do Maranhão. Entende-se, ainda, que o Núcleo Permanente estadual deve centralizar o controle sobre esses dados, a fim de evitar a divulgação de informações equivocadas sobre o status de desenvolvimento da política judiciária no estado.

Segundo o Relatório de Gestão desenvolvido durante o biênio 2012/2013, divulgado no Portal do Poder Judiciário do Estado do Maranhão, em 19 de março de 2013 (MARANHÃO, 2013), foram desenvolvidas as seguintes ações, segmentadas como político-administrativas e executivas (Tabelas 1 e 2):

Tabela 1 - Ações político-administrativas do Núcleo Permanente de Métodos Consensuais de Solução de Conflitos - NUPECON - Biênio 2012/2013

Ações político-administrativas do Núcleo Permanente de Métodos Consensuais de Solução de Conflitos - NUPECON 


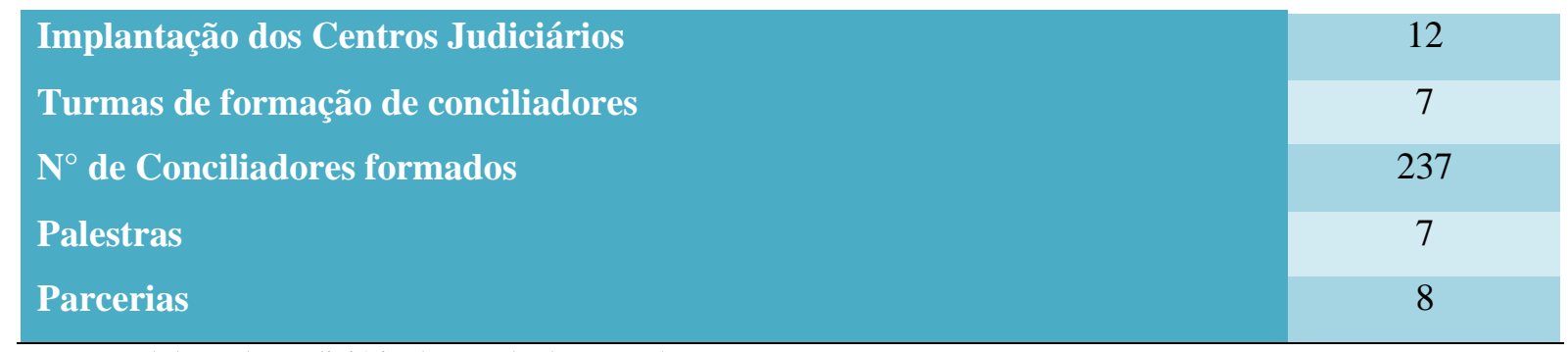

Fonte: Portal do Poder Judiciário do Estado do Maranhão.

Tabela 2 - Ações executivas do Núcleo Permanente de Métodos Consensuais de Solução de Conflitos NUPECON - Biênio 2012/2013

\begin{tabular}{lc}
\hline $\begin{array}{l}\text { Ações executivas desenvolvidas pelos } \mathbf{1}^{\circ} \text { e } 2^{\circ} \text { Centros Judiciários de Solução de Conflitos - São } \\
\text { Luís }\end{array}$ \\
\hline $\begin{array}{l}\text { Requisições de audiências } \\
\text { Audiências realizadas }\end{array}$ & 1482 \\
Audiência com acordo & 795 \\
Audiência sem acordo & 546 \\
\hline
\end{tabular}

Fonte: Portal do Poder Judiciário do Estado do Maranhão

Atualmente foi editada a Resolução-GP-182015 (MARANHÃO, 2015), que regulamenta a organização e o funcionamento do Núcleo Permanente de Métodos Consensuais de Solução de Conflitos no âmbito do Tribunal de Justiça do Estado do Maranhão. A iniciativa é inovadora, pois desde a criação do Núcleo Permanente de Métodos Consensuais de Solução de Conflitos não existia um regulamento que dispusesse especificamente sobre a atuação do Núcleo Permanente na esfera estadual.

A nova Resolução-GP-182015 adotou uma nova terminologia para o Núcleo Permanente de Métodos Consensuais de Solução de Conflitos do Tribunal de Justiça do Estado do Maranhão, o qual passa a denominar-se NUPEMEC.

O NUPEMEC está vinculado à Presidência do Tribunal de Justiça do Estado do Maranhão e, de acordo com o art. $2^{\circ}$ da Resolução-GP-182015, sua composição abrange: i) um desembargador ativo ou inativo, indicado pelo Pleno do Tribunal de Justiça, a quem caberá a Presidência do Núcleo; ii) oito juízes de Direito das comarcas que integram a área de competência das turmas Recursais, indicados pelo Pleno do Tribunal de Justiça; iii) um secretário indicado pelo presidente do NUPEMEC (MARANHÃO, 2015).

A nomeação dos membros do NUPEMEC se dará por ato do presidente do Tribunal de Justiça do Estado do Maranhão a cada dois anos, visando coincidir com o biênio da administração do Tribunal de Justiça do Estado do Maranhão. 
A recondução ao cargo não foi contemplada na legislação administrativa estadual, porém entendemos que mesmo não estando contemplada, não existe qualquer óbice à renovação da respectiva nomeação por igual prazo.

O parágrafo $2^{\circ}$ do art. $2^{\circ}$ da Resolução-GP-182015 vedou a remuneração adicional, a qualquer título, para os membros que vierem a exercer funções junto ao NUPEMEC, o que demonstra a intenção do legislador em vincular as atividades exercidas pelos membros do NUPEMEC como sendo comuns e vinculadas à função regular da judicatura.

O cargo de Coordenador do NUPEMEC caberá ao juiz da Regional com sede na cidade de São Luís, conforme dicção definida no parágrafo $3^{\circ}$ do art. $2^{\circ}$ da Resolução-GP-182015.

Cabe destacar que, ao longo do tempo, foi possível identificar as reais necessidades para o desenvolvimento das atividades vinculadas à política pública judiciária de tratamento adequado dos conflitos de interesses pelo Núcleo Permanente do Estado do Maranhão, como também verificar a estruturação mais adequada à melhor execução da política, assim como identificar os principais problemas e falhas oriundos da execução da própria política judiciária. Nesse sentido, a Resolução-GP-182015 inovou ao especificar objetivamente a competência dos entes e sujeitos envolvidos diretamente com o funcionamento e atuação do NUPEMEC.

Portanto a Resolução-GP-182015 peculiarizou a competência do Núcleo Permanente de Métodos Consensuais de Solução de Conflitos, e ainda detalhou as atribuições do presidente, da secretaria e dos juízes membros vinculados ao NUPEMEC.

Nesse sentido, o art. $6^{\circ}$ da Resolução-GP-182015 estabeleceu como atribuições do presidente do NUPEMEC: I) instalar o Núcleo; II) indicar o Secretário e demais ocupantes das funções gratificadas, para nomeação pelo TJMA; III) providenciar a implantação e coordenação do Centro de Conciliação e Mediação do $2^{\circ}$ Grau; IV) assinar os convênios e parcerias com entes públicos e privados, para atender aos fins desta Resolução; V) responder perante o CNJ pelo NUPEMEC e CEJUSC's; VI) remeter todos os dados estatísticos e demais informações para conhecimento das ações desenvolvidas pelo NUPEMEC e CEJUSCS's; VII) gerir todas as atividades do NUPEMEC, com o auxílio do Juiz Coordenador; VIII) recomendar que as atividades relacionadas à conciliação, mediação e outros métodos consensuais de solução de conflitos sejam consideradas nas promoções e remoções de magistrados pelo critério do merecimento; IX) expedir, nos limites de sua atribuição e nos termos da Resolução, ofícios circulares, portarias e ordens de serviço (MARANHÃO, 2015). 
De um modo geral, o que se percebe das atribuições outorgadas ao presidente do NUPEMEC é que são de caráter meramente político e administrativo e visam a estreitar a interlocução entre o Tribunal de Justiça do Estado do Maranhão e o CNJ.

Por sua vez, o art. 10 da Resolução-GP-182015 delimitou as atribuições dos juízes membros do NUPEMEC. São elas: I) coordenar as ações voltadas para a política judiciária de tratamento adequado de conflitos de interesses, dando cumprimento às decisões do TJMA; II) auxiliar a Administração Superior do TJMA na interlocução com outros órgãos e instituições, propondo a realização de convênios e parcerias; III) propor a capacitação de magistrados, servidores, mediadores e conciliadores que atuam nos CEJUSCS's; IV) supervisionar as atividades dos CEJUSCS's que lhes são vinculados; V) propor e promover ações voltadas ao estímulo à comunidade quanto ao uso de mecanismos de resolução de conflitos baseados no diálogo; VI) promover a interlocução com a Ordem dos Advogados do Brasil, Defensorias Públicas e Ministério Público, estimulando sua participação nos CEJUSCS's; VII) encaminhar ao presidente do NUPEMEC relatório semestral de atividades desenvolvidas; VIII) exercer atribuições delegadas e demais previstas na Resolução-GP-182015 (MARANHÃO, 2015).

Observa-se que nas atribuições delegadas aos juízes membros estão contidos os reais propósitos, ações e programas definidos pela política pública nacional, pois serão os juízes membros que promoverão a interlocução junto à cúpula administrativa do TJMA, aos servidores, mediadores e conciliadores capacitados para atuarem nos CEJUSCS's. E, ainda, junto às entidades públicas e privadas, de um modo geral.

Uma das grandes novidades na estrutura do NUPEMEC se refere à criação de duas Secretarias: 1) Secretaria do NUPEMEC: destinada a atender ao presidente e aos demais membros do Núcleo, assim como desempenhar as funções próprias de secretaria, inclusive junto ao Centro de Conciliação e Mediação do $2^{\circ}$ Grau (Art. $7^{\circ}$ da Resolução-GP-182015); 2) Secretarias Regionais: com atribuição de atender às microrregiões do Estado e dar apoio às comarcas do interior (Art. 11 da Resolução-GP-182015).

A Secretaria do NUPEMEC terá um quadro de pessoal, compreendendo um secretário; quatro conciliadores/mediadores constantes do quadro permanente do TJMA e previamente capacitados; quatro técnicos também vinculados ao quadro permanente do TJMA e, finalmente, quatro estagiários. Especificamente, as competências do Secretário do NUPEMEC estão previstas no art. $9^{\circ}$ da Resolução-GP-182015.

Por sua vez, as Secretarias Regionais terão uma composição diferenciada em relação à Secretaria do NUPEMEC. Como dispõe o art. 11 da Resolução-GP-182015, o quadro de 
pessoal de cada regional será composta por, no mínimo, três servidores com função comissionada ou concursados com função gratificada, cabendo a um deles a função de secretário do polo. A nomeação do secretário do polo deverá, na forma do $\S 3^{\circ}$ do art. 11 da Resolução-GP-182015, observar as restrições e impedimentos de nepotismo direito e transversal, previstos na Resolução $n^{\circ}$ 07/05 do CNJ (BRASIL, 2005). As competências da secretaria estão previstas no art. 12 da Resolução-GP-182015 e compreendem, dentre outras atividades, o atendimento às partes, aos procuradores e ao público em geral. Como também, ficará responsável pela guarda de documentos e elaboração de dados estatísticos.

Reza o art. 13 da Resolução-GP-182015 que todos os servidores da Secretaria Regional deverão estar capacitados para: I) recepcionar os interessados no agendamento de audiências ou sessões de mediação ou de conciliação; II) realizar a triagem dos casos, encaminhando-os para os setores competentes; III) realizar as sessões de conciliação e mediação, e IV) promover a instrução de conciliadores (MARANHÃO, 2015).

Caberá ao Tribunal de Justiça do Estado disponibilizar cursos de capacitação, treinamento e aperfeiçoamento dos servidores vinculados às Secretarias Regionais, e, ainda, firmar parcerias que visem atingir a essa finalidade, como consubstancia o parágrafo único do art. 13 da Resolução-GP-182015.

Apesar da Resolução-GP-182015 contemplar essa estrutura grandiosa para possibilitar a organização do Núcleo Permanente de Métodos Consensuais de Solução de Conflitos no Estado do Maranhão, até o momento não foi editada a lei que cria os cargos necessários ao funcionamento do NUPEMEC, o que nos leva a concluir que a estrutura complexa do NUPEMEC existe na mera intenção e no 'papel'.

\section{CONCLUSÃO}

Neste artigo pretendeu-se verificar como ocorreu a estruturação dos Núcleos Permanentes de Métodos Consensuais de Solução de Conflitos, a partir das diretrizes apontadas na Resolução CNJ n ${ }^{\circ}$ 125/2010, que primou pela implantação de um novo modelo de atuação do Poder Judiciário, baseado na utilização de meios consensuais de solução de conflitos de interesses, no sentido de promover um afastamento à solução adjudicada por meio da sentença judicial. 
Verificou-se que o Conselho Nacional de Justiça, apesar de exercer a centralidade em relação às diretrizes traçadas pela política judiciária, acaba por transferir a responsabilidade dos programas e ações aos tribunais, na medida em que define metas de produtividade que exigem o cumprimento das orientações contidas na Resolução CNJ n ${ }^{\circ}$ 125/2010.

Concluiu-se que os Núcleos Permanentes de Métodos Consensuais de Solução de Conflitos assumem a função de dar coesão às práticas direcionadas à autocomposição dos conflitos de interesses no âmbito do Judiciário, bem como orientam o desenvolvimento da política no âmbito regional e/ou estadual.

Especificamente, em relação ao papel assumido e desempenhado pelo Núcleo Permanente de Métodos Consensuais de Solução de Conflitos no Estado do Maranhão, averiguou-se que a sua forma de organização estrutural e funcional obedeceu estritamente às diretrizes nacionais estabelecidas pela Resolução CNJ n 125/2010 sem, no entanto, avançar na definição de uma agenda política das ações a serem programadas e executadas no âmbito estadual.

\section{REFERÊNCIAS}

BOURDIEU, Pierre. O poder simbólico. Tradução: Fernando Tomaz. 10. ed. Rio de Janeiro: Bertrand Brasil, 2007.

BRASIL. Conselho Nacional de Justiça. Emenda n ${ }^{\circ}$ 1, de 31 de janeiro de 2013. Altera os arts. $1^{\circ}, 2^{\circ}, 6^{\circ}, 7^{\circ}, 8^{\circ}, 9^{\circ}, 10,12,13,15,16,18$ e os Anexos I, II, III e IV da Resolução ${ }^{\circ} 125$, de 29 de novembro de 2010. Brasília: CNJ, 2013. Disponível em: <http://www.cnj.jus.br/images/emenda_gp_1_2013.pdf>. Acesso em: 10 nov. 2015.

Conselho Nacional de Justiça. Portaria ${ }^{\circ}$ 637, de 09 de outubro de 2009. Instituir Comitê Gestor da Conciliação com o propósito de dar continuidade ao projeto de divulgação e incentivo da solução de conflitos por meio da conciliação e de organizar e implementar ações para a Semana Nacional da Conciliação. Brasília: CNJ, 2009. Disponível em: <http://www.cnj.jus.br/files/atos_administrativos/portaria-n637-09-10-2009-presidncia.pdf>. Acesso em: 4 out. 2015.

Conselho Nacional de Justiça. Portaria ${ }^{\circ}$ 141, de 20 de julho de 2010. Institui grupo de trabalho para realizar estudos e propostas de ações com vistas à concretização de uma 
política nacional de conciliação. Brasília: CNJ, 2010a. Disponível em: <http://aplicacao.tst.jus.br/dspace/bitstream/handle/1939/34440/2010

_port0141_cnj.pdf?sequence=1>. Acesso em: 4 out. 2015.

. Conselho Nacional de Justiça. Relatório Justiça em Números 2009 - Panorama do Judiciário Brasileiro (Sumário Executivo). Brasília: CNJ, set. 2010b. Disponível em: <http://www.cnj.jus.br/images/programas/justica-em-numeros/rel_sumario_exec_jn2009.pdf>. Acesso em: 10 ago. 2015.

Conselho Nacional de Justiça. Resolução nº ${ }^{\circ}$ 7/05, de 18 de outubro de 2005. Disciplina o exercício de cargos, empregos e funções por parentes, cônjuges e companheiros de magistrados e de servidores investidos em cargos de direção e assessoramento no âmbito dos órgãos do Poder Judiciário e dá outras providências. Brasília: CNJ, 2005. Disponível em: <http://www.cnj.jus.br/images/stories/docs_cnj/resolucao/rescnj_07.pdf>. Acesso em: 2 out. 2015.

Conselho Nacional de Justiça. Resolução n ${ }^{\circ}$ 125, de 29 de novembro de 2010.

Dispõe sobre a Política Judiciária Nacional de tratamento adequado dos conflitos de interesses no âmbito do Poder Judiciário e dá outras providências. Brasília: CNJ, 2010c. Disponível em: <http://www.cnj.jus.br/images/stories/docs_cnj/resolucao/arquivo_integral_republicacao_resoluca o_n_125.pdf>. Acesso em: 1 mar. 2013.

GABBAY, Daniela Monteiro; CUNHA, Luciana Gross (Orgs.). Litigiosidade, morosidade e litigância repetitiva no judiciário: uma análise empírica. São Paulo: Saraiva, 2012. (Coleção direito, desenvolvimento e justiça: série produção científica)

LUCHIARI, Valeria Ferioli Lagrasta. A Resolução $n^{\circ} 125$ do Conselho Nacional de Justiça: origem, objetivos, parâmetros e diretrizes para a implantação concreta. In: PELUSO, Antonio Cezar; RICHA, Morgana de Almeida (Coords.). Conciliação e mediação: estruturação da política judiciária nacional. Rio de Janeiro: Forense, 2011.

MARANHÃO. Tribunal de Justiça do Estado. Resolução-GP-102011, de 16 de março de 2011. Dispõe sobre a Política Estadual de treinamento adequado dos conflitos de interesses no âmbito do Poder Judiciário e dá outras providências. São Luís, 2011. Disponível em: 
<http://gerenciador.tjma.jus.br/app/webroot/files/publicacao/106908/28112012_1624_1.pdf>.

Acesso em: 2 nov. 2015.

2012.

_. Tribunal de Justiça do Estado. Por

aria-GP-2082012, de 29 de fevereiro de

$<$ http://gerenciador.tjma.jus.br/app/webroot/files/publicacao/403744/portaria-

gp2082012_25102013_1240.pdf>. Acesso em: 2 nov. 2015.

. Tribunal de Justiça do Estado. Relatório de Gestão - biênio 2012/2013 do

Núcleo Permanente de Métodos Consensuais de Solução de Conflitos. São Luís, 2013.

Disponível

em:

<http://gerenciador.tjma.jus.br/app/webroot/files/publicacao/401657/relatorio_de_gestoo_bionio_ 2012-2013_05112013_0931.pdf>. Acesso em: 15 out. 2015.

Tribunal de Justiça do Estado. Resolução-GP-182015, de 22 de abril de 2015. Regulamenta a organização e o funcionamento do Núcleo Permanente de Métodos Consensuais de Solução de Conflitos, bem como altera a Resolução n 20/2010 e revoga a Resol-GP-102011, de 16 de março de 2011, ambas do Tribunal de Justiça do Estado do Maranhão. São Luís, 2015. Disponível em: <http://gerenciador.tjma.jus.br/app/webroot/files/publicacao/408999/resoluooogp-182015_11052015_1131.pdf>. Acesso em: 2 nov. 2015.

NOGUEIRA, Mariella Ferraz de Arruda Pollice. Dos Núcleos Permanentes de Métodos Consensuais de Solução de Conflitos. In: PELUSO, Antonio Cezar; RICHA, Morgana de Almeida (Coords.). Conciliação e mediação: estruturação da política judiciária nacional. Rio de Janeiro: Forense, 2011.

PELUSO, Cezar. [Discurso de posse]. Disponível em: <http://www.stf.jus.br/arquivo/cms/noticiaNoticiaStf/anexo/discursoPeluso.pdf $>$. Acesso em: 4 nov. 2015. 